\title{
DIAGNÓSTICOS DAS NECESSIDADES HUMANAS BÁSICAS NO CONTEXTO SÓCIO-FAMILIAR DE CRIANÇAS DESNUTRIDAS
}

\author{
Mirna Albuquerque Frota ${ }^{1}$, Rosalba Maria Viana de Sousa ${ }^{2}$, \\ Osvaldo Albuquerque Sousa Filho ${ }^{3}$, Maria GrasielaTeixeira Barroso ${ }^{4}$
}

\begin{abstract}
RESUMO: Pesquisa qualitativa, por meio do método exploratório, com o objetivo de identificar os diagnósticos das Necessidades Humanas Básicas (NHB's) de crianças desnutridas residentes na periferia de Fortaleza-CE e caracterizar o contexto sócio-familiar das mesmas. Realizada com uma família assistida pelo Centro de Desenvolvimento Familiar - CEDEFAM/Fortaleza. Os dados foram coletados por observações oriundas das visitas domiciliares e depoimentos da mãe. A análise dos diagnósticos de enfermagem apreendidos foi embasada no referencial de NHB. Os problemas mais evidenciados decorrem do baixo nível sócio-econômico-cultural, assim como o desconhecimento sobre a desnutrição se reflete na evolução da doença. Conclui-se que existe a necessidade da implementação de ações educativas em saúde que envolvam a participação da família e que priorizem a prevenção de riscos a doenças, objetivando reduzir a mortalidade infantil.
\end{abstract}

PALAVRAS-CHAVE: Diagnóstico de enfermagem; Enfermagem pediátrica; Família; Transtorno da nutrição infantil.

\section{DIAGNOSES OF BASIC HUMAN NEEDS IN UNDERNOURISHED CHILDREN'S SOCIO-FAMILIAR CONTEXT}

\begin{abstract}
Aimed to investigate the socio-familiar context of undernourished children, residents in the outskirts of Fortaleza-CE/ Brazil, and to identify their Basic Human Needs (BHN"s). Qualitative research, in three phases: exploratory, family selection, data collection and analysis and conclusion. It was carried out with a family assisted by the Family Development Center - CEDEFAM/ Fortaleza. Data were collected through observation during home visits as well as mother's accounts. The analysis of the apprehended nursing diagnoses was grounded on the BHNs. The most evident problems result from the low socio-economic and cultural level, as well as unknowing the undernourishment problematic reflects on the illness evolution. It can be concluded that educational actions need to be implemented, involving family participation, pointing out illness prevention, thus reducing child death rate.
\end{abstract}

KEYWORDS: Nursing Diagnosis; Pediatric Nursing; Family; Child nutrition disorders.

\section{DIAGNÓSTICO DE LAS NECESIDADES HUMANAS BÁSICAS EN EL CONTEXTO SOCIOFAMILIAR DE NINÕS DESNUTRIDOS}

RESUMEN: El objetivo fue investigar el contexto sociofamiliar de niños desnutridos, residentes en la periferia de Fortaleza, CE e identificar los diagnósticos de las Necesidades Humanas Básicas (NHB's) de niños desnutridos. Investigación cualitativa, en tres fases: exploratoria, selección de la familia, colecta y análisis de los datos y conclusión. Realizada con una familia asistida por el Centro de Desarrollo Familiar - CEDEFAM/Fortaleza. Los resultados fueron evidenciados por observaciones hechas en las visitas domiciliares, declaraciones de la madre y basadas en el Diagnóstico de Enfermería. Los problemas más evidenciados fueron causados por el bajo nivel socioeconómico y cultural, así como por el desconocimiento de la problemática desnutrición que se refleja en la evolución de la enfermedad. Es una necesidad acuciante la implementación de acciones educativas que envuelvan la participación de la famlia, transmitiendo así prácticas en salud que prioricem la prevención de dolencias de riesgo, con el objetivo de reducir la mortalidad infantil.

PALABRAS CLAVE: Diagnóstico de enfermería; Enfermería pediátrica; Familia; Transtornos de la nutricion del ninõ.

\footnotetext{
${ }^{1}$ Doutora em Enfermagem. Professora Adjunta do Curso de Graduação em Enfermagem e do Mestrado em Educação em Saúde da Universidade de Fortaleza.

${ }^{2}$ Especialista em Saúde Pública. Enfermeira do Programa de Saúde da Família.

${ }^{3}$ Mestre em Educação em Saúde. Professor do Curso de Graduação em Enfermagem da Faculdade Grande Fortaleza - FGF. Enfermeiro assistencial do Instituto Dr. José Frota - IFJ.

${ }^{4}$ Enfermeira. Professora Emérita da Universidade Federal do Ceará - UFC.
}

Autor correspondente:

Mirna Albuquerque Frota

R Manuel Jacaré, 150, ap. 1401 - 60175-110 - Fortaleza-CE Recebido em: 24/04/07

mirnafrota@unifor.br 


\section{INTRODUÇÃO}

Desnutrição é um termo que se aplica à nutrição inadequada ou deficiente, sendo um dos mais sérios problemas na área de saúde, liderando causas de morbimortalidade na infância. $\mathrm{O}$ estado nutricional, a renda, tamanho, crenças e costumes da família, nível educacional dos pais, custos, valor nutricional dos alimentos e disponibilidade de serviços e equipamentos de saúde são considerados multifatores referentes à problemática da desnutrição infantil ${ }^{(1,2)}$. Entretanto, as causas fundamentais da desnutrição obedecem às deficiências da organização social, destacando-se a questão da ignorância no que diz respeito aos padrões alimentares como fator determinante de agravos nutricionais, uma vez que a pobreza de conhecimentos é causa relevante da desnutrição infantil, ultrapassando algumas vezes a pobreza econômica. Outra vertente referente à causalidade da desnutrição é o fator cultural, considerando o saber de experiência, de conhecimento adquirido no decorrer da vida, transmitida de geração em geração por intermédio da família, escola e igreja. As relações político-pedagógicas requerem também um olhar diferenciado no que se refere à multicausalidade da desnutrição infantil.

Diante desta problemática, percebe-se a vulnerabilidade em que se encontram essas famílias, portanto surgem diversificados questionamentos, como por exemplo, qual o contexto sócio-cultural da família de criança desnutrida? Quais as necessidades humanas básicas enfrentadas? Quais os demais fatores que contribuem para este quadro? Qual a percepção da mãe sobre a desnutrição do seu filho, levando em conta os aspectos culturais e o modo de vida dessas famílias?

No Brasil, a desnutrição do tipo marasmática é predominante e, no Nordeste, a situação é mais grave, com as áreas atingidas pela seca, como também em favelas urbanas resultantes do crescimento do êxodo rural e provenientes da ausência de perspectivas de melhoria na qualidade de vida. Relaciona-se, ainda, ao desemprego ou sub-emprego familiar, alimentação carente, ou precária, saneamento básico escasso, educação em saúde e assistência básica inexistentes, falta de moradia. Ressalta-se que a desnutrição permanece como um grande problema de saúde pública $^{(2,3)}$. Portanto, a criança brasileira paga um alto preço pela pouca e desordenada evolução, com morte prematura e por outras causas evitáveis de doenças. Grande parte da população infantil brasileira não tem o que comer, onde morar e vive em verdadeiros cubículos, em condições habitacionais desumanas, revelando que cada dia é uma incerteza diante de algo que deveria ser um direito adquirido de todos, acesso ao alimento.

Desde a concepção da criança, até a sua maturidade, acontecem inúmeras transformações, necessitando de condições favoráveis para a realização de suas potencialidades. Assim sendo, torna-se difícil um crescimento satisfatório acompanhado de problemas crônicos como a desnutrição. Como proteção a essa vulnerabilidade, a natureza disponibiliza o aleitamento materno, que do ponto de vista nutricional é capaz de suprir com suas vantagens bioquímicas, digestivas e econômicas as necessidades alimentares da criança durante os seis primeiros meses de vida.

Diante do exposto, o que se revela muitas vezes, é que a desnutrição do filho caracteriza-se como um reflexo da saúde da mãe, ou seja, a condição de mães desnutridas se reflete na saúde de seus filhos, pois as gestantes e depois as mães que amamentam têm uma necessidade aumentada de nutrientes para prevenir a própria subnutrição e do bebê.

Cabe ressaltar que o ponto primordial da educação nutricional não é o de ensinar habilidades de apropriação de poder, e sim o de como utilizar melhor os recursos, e neste caso, os métodos mais convencionais de educação nutricional, tais como a mudança de hábitos alimentares e sanitários, podem se tornar eficazes. O setor saúde pode contribuir com a educação nutricional a curto e médio prazos para uma efetiva redução do quadro de deficiências nutricionais. Para isso, se utiliza de uma série de instrumentos de comprovada eficácia, como o diálogo, incentivando uma comunicação efetiva, que é essencial para a educação e para as relações humanas. O homem, independentemente de ser ou não alfabetizado, é capaz de captar os dados da realidade, para ser capaz de saber e com esse saber transformar a sua realidade ${ }^{(3,4)}$.

A educação em saúde, como área de conhecimento, articula saúde e educação, traz as marcas de influências históricas e sociais e se reflete ainda hoje modos de explicar as múltiplas causas das doenças e das condições de adoecer ${ }^{(5)}$. Assim, os profissionais de saúde e a população devem 
compreender que a saúde não depende apenas das ações do cuidado que são oferecidas pelos serviços, mas que a prevenção de qualquer enfermidade é uma conseqüência da educação da população. Desta forma, os serviços de saúde devem proporcionar às comunidades, meios de se beneficiarem com a disponibilidade das informações educativas, a fim de proporcionar uma transformação da sua concepção de saúde.

Os objetivos deste estudo são: identificar os diagnósticos das Necessidades Humanas Básicas (NHB's) de crianças desnutridas residentes na periferia de Fortaleza-CE e caracterizar o contexto sócio-familiar de crianças desnutridas.

\section{DESCRIÇÃO DO MÉTODO}

Este é um estudo com referencial da pesquisa qualitativa, modalidade que responde às questões particulares, num espaço mais profundo das relações, considerando como sujeitos do estudo pessoas pertencentes a determinada condição social, com suas crenças e valores $^{(6,7)}$. A opção deve-se à necessidade de compreensão do fenômeno da experiência familiar na situação de desnutrição, buscando apreender o significado do mesmo e integrar os aspectos gerais da desnutrição ao contexto em que vivem essas crianças, ao conjunto de relações vivenciadas pelas mães. Utilizou-se o diagnóstico de enfermagem com base nas Necessidades Humanas Básicas (NHB) de acordo com Carpenito ${ }^{(8)}$, com o intuito de identificar a situação da família e oferecer maior subsídio para a investigação.

A pesquisa foi realizada na cidade de Fortaleza, que com o crescimento do êxodo rural, apresenta a superlotação nas favelas, aumentando conseqüentemente, a criminalidade, a prostituição e a violência. Ocorreu no centro de Desenvolvimento Familiar - CEDEFAM/Fortaleza, que é integrado à PróReitoria e Extensão da Universidade Federal do Ceará UFC e dividido em três unidades: Unidade do Cuidado de Enfermagem (UCE); Unidade Odontológica e Unidade de Farmácia-viva. A UCE presta serviço por meio do acompanhamento da saúde de famílias com consultas de enfermagem e visitas domiciliares.

Uma família foi escolhida mediante a análise de 120 prontuários, consultas de enfermagem e visitas domiciliares. O critério de seleção foi a condição sócio-econômica e a gravidade da desnutrição na criança, optando-se pela classificação marasmática, sendo a criança selecionada extremamente magra devido à perda de músculo e gordura corporal ${ }^{(3)}$.

Realizou-se um estudo em três fases. Inicialmente foi feita a exploração dos prontuários e observações diretas de mães, no momento das consultas de enfermagem. Na segunda fase foi selecionada a família, contendo uma criança que se enquadrou no critério de inclusão, sendo iniciado o acompanhamento, mediante as visitas domiciliares e utilizando-se a técnica de observação participante. A continuidade da coleta de dados ocorreu mediante entrevista com a mãe considerando a questão norteadora: Como você percebe seu filho desnutrido?

O rigor ético esteve presente em todo o processo do estudo, em consonância com a Resolução do CNS 196/96 $6^{(9)}$, incorporando os referenciais básicos da bioética: autonomia, não-maleficência, beneficência e justiça. Foi assinado pela mãe o Termo de Consentimento Livre e Esclarecido, no qual constou o objeto do estudo, o objetivo, a estratégia de implementação e o modo de inserção da mãe, ficando ainda assegurado o direito à desistência, por qualquer tempo e motivo. A pesquisa está vinculada ao projeto "Desnutrição infantil: educação e prevenção através da família", aprovado pelo Comitê de Ética em Pesquisa da Universidade de Fortaleza - UNIFOR.

A análise dos dados baseou-se em Minayo ${ }^{(6)}$ cujo método caracteriza-se pela descrição e documentação das falas dos informantes, seguidas da codificação aberta dos dados e, por fim, a síntese do pensamento, análise da configuração, interpretação dos achados e formulação criativa dos achados, dando origem à caracterização da família e elaboração dos diagnósticos de enfermagem.

\section{RESULTADOS}

Como ponto inicial dos resultados, apresentase a caracterização da família, composta por oito membros: a mãe, 38 anos; o pai, 54 anos; e seis filhos, dos quais quatro são crianças $(6,4$ e 2 anos e a criança do estudo com 1 mês de idade). Eles vivem com uma renda mensal de 01 salário mínimo, em que 120 reais são gastos com o aluguel da casa e o restante com alimentação. O pai é o único provedor da família e trabalha como carregador de caminhão. O nível de escolaridade dos pais é o do ensino fundamental incompleto. A família reside em um bairro periférico 
de Fortaleza, em que as condições de pobreza revelam a dificil busca pela sobrevivência, ressaltando a moradia e a alimentação deficientes. A família, apesar dos problemas financeiros, vive uma relação harmoniosa, de amizade e intimidade. A comunicação entre os membros é favorável e o diálogo freqüente.

Por meio da observação participante, percebeuse que no âmbito familiar existem outras crianças desnutridas. Elas passam a maior parte do dia deitadas em redes ou assistindo televisão, não freqüentam a escola e conseqüentemente, existe um possível déficit de conhecimento com relação ao processo de desnutrição.

A experiência da mãe caracteriza-se pela demonstração de algum conhecimento sobre o processo saúde/doença, sabendo-se que a saúde é um estado de bem-estar que se reflete na capacidade dos indivíduos em realizar suas atividades diárias, de maneira satisfatória ${ }^{(10)}$. Vencidos os obstáculos iniciais do estigma da desnutrição, surgem, então, diferentes sentimentos, observados durante a coleta dos dados, como por exemplo, o pouco envolvimento afetivo com o filho doente parecendo dificultar a aceitação da doença. Isso se pode evidenciar nos relatos da mãe:

Desde que ela nasceu que é assim, pouquinha. É de família, todos são magros. Não acho que ela seja desnutrida. Aqui os vizinhos todos chamam minha filha de desnutrida, só porque ela é magrinha.

Eu sei que ele está doente quando ele não quer comer, não brinca, fica mole e só quer dormir.

O fraco vínculo mãe/filho pode ser também desencadeado quando os seguintes indicadores estão presentes: gestação indesejada, problemas emocionais no decurso da gestação, distúrbios do sono no lactente, choro e cólicas intensas, dificuldades de amamentação e ansiedade materna ${ }^{(11)}$.

Os depoimentos evidenciados revelam o cotidiano da desnutrição, baseada na consciência da mãe de que a alimentação é deficitária no âmbito familiar e fazendo de imediato a relação com a condição sócio-econômica, caracterizando uma subvida conturbada. Assim, o dia-adia se torna uma verdadeira luta pela sobrevivência. A criança desnutrida nesse ambiente torna-se susceptível a doenças e requer hospitalização mais freqüente e por períodos longos ${ }^{(2)}$.

Às vezes ela pede comida, mas eu não tenho para dar. O dinheiro mal dá para pagar o aluguel da casa.
$\mathrm{Na}$ dimensão saúde-doença, a mãe retrata desconhecimento sobre o problema da desnutrição. Isso resulta em retardar, algumas vezes, o processo de reabilitação da criança com informações que poderiam contribuir na recuperação, tendo como exemplo: conhecer as preferências nutricionais da criança dentro de sua realidade sócio-econômica.

Os agravos nutricionais decorrem de fatores sociais e biológicos, os quais se encontram intrinsecamente relacionados. Quando se fala em baixo peso ao nascer, episódios diarréicos, infecções respiratórias, parasitoses, desnutrição, etc, que são fenômenos biológicos, de algum modo também se refere à ausência de pré-natal, carência de saneamento básico, poluição ambiental, enfim, precariedade do ambiente, que são fenômenos decorrentes da desigualdade social. Assim, o desmame precoce, que pode ser decorrente da desnutrição, revela-se no relato da mãe como determinante:

Ela nunca quis mamar. Sempre que colocava no peito, ela ficava chorando, não mamava, ai eu fazia mingau de leite. Quando não tinha o leite, eu fazia d'água mesmo. Foi indo, foi indo, até que o leite acabou.

O depoimento, significativo, constata a visão da mãe sobre a relação entre a desnutrição do filho com o desmame precoce. A impossibilidade de manter o aleitamento materno efetivo e o conseqüente desmame precoce podem estar relacionados à desnutrição, falta de motivação da mãe para amamentar, insuficiência de informações sobre os reais benefícios do leite materno, falta de suporte familiar, preparo emocional, condições físicas como repouso e alimentação adequada, entre outros fatores, os quais reunidos conformam o sucesso ou não do aleitamento materno. A desnutrição acontece quando a alimentação é escassa, não contém quantidade suficiente de nutrientes que fornecem proteína e energia e ainda, algumas doenças modificam as necessidades nutricionais da criança. Também se fez presente no estudo o desconhecimento quanto à conduta adequada em situações de diarréia, levando à suspensão da oferta de alimentos básicos por tempo maior que o necessário, com decorrente prejuízo nutricional.

Com base no exposto, foi possível identificar os diagnósticos de enfermagem com sustentação no referencial das NHB, que descreve um tipo específico de problema ou de resposta que a enfermeira identifica ${ }^{(11)}$. Ressalta-se ainda que as necessidades são identificadas, conforme o encontro e reconhecimento da 
família, pois assim é possível que a intervenção se baseie na projeção de suas próprias necessidades ${ }^{(12-13)}$. Foi percebido, mediante o conteúdo da entrevista com a mãe e pelas observações da criança, que esta apresentava crescimento e desenvolvimento alterados, caracterizado pelo crescimento abaixo do percentual incapacitando-a de realizar as tarefas compatíveis com seu grupo etário. $\mathrm{O}$ fato fica evidenciado no relato da mãe:

\section{[...] a criança está fraca, e por isso não está} freqüentando a escola.

Nas populações de países subdesenvolvidos é comum as crianças em idade escolar apresentarem déficit de crescimento, haja vista que a principal adaptação metabólica à desnutrição é a redução na velocidade de crescimento físico ${ }^{(3)}$.

Nas interações com a família, observou-se a troca de papéis, uma vez que a mãe aceita que as crianças sejam submissas ao irmão mais velho, na ausência do pai, podendo vir a comprometer a educação dos filhos.

A mãe expressa percepção incorreta acerca do estado de saúde da filha pois, acredita que o baixo peso está relacionado a condições genéticas, quando afirma que todos na família são magros. Por isso, se recusa a levá-la para tratamento, pois não acredita na desnutrição da fillha. Observou-se um possível sentimento de negação do quadro de desnutrição, quando a mãe relata que a criança está gripada, assim como foi predominante o receio pela internação da filha, retratando preocupação pelos demais filhos que ficariam em casa, representando para a mãe que o tratamento de um filho vem a ser o "abandono" dos outros.

Mediante as observações, foi percebido que a criança apresenta nutrição alterada: menor do que as necessidades corporais, sendo justificada pela mãe por meio das dificuldades financeiras e que a renda é insuficiente, sobretudo para alimentação da família. Portanto, percebeu-se que o alimento, além de freqüentemente escasso, quando está presente é predominantemente característico de alimentos não saudáveis, podendo levar à futuros diagnósticos das $\mathrm{NHB}^{(8)}$, tais como: risco para infecção relacionada à desnutrição, risco para lesão relacionada à má nutrição, integridade tissular prejudicada relacionada à mobilidade física prejudicada, membrana mucosa oral alterada, e deglutição prejudicada relacionada à recusa de alimentos.
Detectou-se ainda, um diagnóstico de amamentação ineficaz, sendo definido como insatisfação ou dificuldade a incapacidade do bebê de agarrar corretamente o seio da mãe, o que foi identificado no relato anterior da mãe.

A maioria das crianças desnutridas provêm de ambientes em que a má-nutrição, a pobreza e a ignorância são concomitantes e, sob tais circunstâncias elas podem não só sofrer de escassez de alimentos, como também de estímulos psicosociais $^{(14)}$. A família encontra-se em condições economicamente precárias e foi possível observar na moradia a desorganização e presença de sujidades, sinal de seus membros não terem motivação para realizar a higiene do lar.

A vida diária da família não pode ser vista como isolada, mas inserida na dinâmica política e econômica da sociedade como um todo. As famílias, principalmente as de classes menos favorecidas, demonstram, muitas vezes, uma aceitação frente às relações de dominação presentes em nossa sociedade. Assim, o grande desafio como profissionais é cuidar com a perspectiva da totalidade, valorizando a dimensão subjetiva e resgatando o sentido humanitário nas relações interpessoais, priorizando a participação da família com vistas à promoção da saúdE(15)

\section{CONSIDERAÇÕES FINAIS}

O contexto familiar revela que a desnutrição interfere diretamente no estilo de vida da criança, e que os problemas evidenciados decorrem do baixo nível sócio-econômico-cultural, assim como o déficit da consciência a cerca da problemática da desnutrição, refletindo-se conseqüentemente na evolução da doença.

Considera-se, portanto, que a desnutrição é um indicador de pobreza, e que na população de baixa renda se encontra a quase totalidade das crianças desnutridas, normalmente não alcançadas por políticas de saúde. Pode-se dizer que uma das causas da mortalidade infantil no Brasil está centrada na deficiência de cuidados com o recém-nato até seu primeiro mês de vida.

Com base no exposto, torna-se importante levar à população ações práticas para prevenir doenças de risco, objetivando reduzir a mortalidade infantil. Um momento relevante e que deveria ser 
desenvolvido esse trabalho é durante o pré-natal, visando conscientizar as mães da importância do aleitamento materno exclusivo e dos cuidados adequados ao recém-nascido.

Ressalta-se, portanto, a responsabilidade do profissional de Enfermagem na assistência ao paciente desnutrido que está centrada na observação dos índices antropométricos para a avaliação da condição nutricional, na orientação de cuidados higiênicos às mães, assim como na responsabilidade pelas medicações, coleta de exames, encaminhamento e orientação sobre os serviços de planejamento familiar, assim respondendo às necessidades humanas básicas. O estudo mostra a necessidade de criação de grupos de discussão para as mães de crianças desnutridas, mediante estratégias educativas, assim como revela a importância da visita domiciliar, objetivando o suporte familiar, a atenção continuada, a avaliação do crescimento, do desenvolvimento, do equilíbrio psicoafetivo da criança e família e identificação precoce de riscos e danos.

\section{REFERÊNCIAS}

1 Valente FLS. Fome e desnutrição: determinantes sociais. São Paulo: Cortez; 1989.

2 Frota MA, Barroso GT. Desnutrição infantil na família: causa obscura. Sobral: UVA; 2003.

3 Ferreira HS. Desnutrição: magnitude, significado social e possibilidades de prevenção. Maceió: EDUFAL; 2000.

4 Freire P. Educação como prática da liberdade. Rio de Janeiro: Paz e Terra; 1994.

5 Barroso GT, Vieira NFC, Varela, ZMV. Educação em saúde no contexto da produção humana. Fortaleza: Demócrito Rocha; 2003.

6 Minayo MCS. O desafio do conhecimento: pesquisa qualitativa em saúde. $9^{a}$ ed. São Paulo: Hucitec; 2006.

7 Vieira NFC, Vieira LJES, Frota MA. Reflections on the ethnographic approach in three research studies. Rev Latino-am Enferm. 2003;11(5):658-63.

8 Carpenito LJ. Diagnósticos de enfermagem: aplicação à prática clínica. Porto Alegre: Artmed; 2002.

9 Ministério da Saúde (BR). Resolução nº 196. Diretrizes e normas técnicas regulamentadoras de pesquisas envolvendo seres humanos. Brasília: Ministério da Saúde; 1996.

10 George JB. Teorias de enfermagem: fundamentos para a prática profissional. Porto Alegre: Artmed; 1993.

11 Nóbrega FJ, Campos ALR, Nascimento CFL. Distúrbios nutricionais e o fraco vínculo mãe/filho. Rio de Janeiro: Revinter; 2000.

12 Frota MA, Barroso MGT, Varela ZMV. A adolescente e o filho desnutrido: cuidado cultural. Fam Saúde Desenv. 1999;1(1/2):97-101.

13 Frota MA, Barroso MGT. Cuidado cultural à criança desnutrida filha de adolescentes. In: Barroso MGT, Vieira NFC, Varela ZMV, organizadores. Saúde da família II: espaço de incertezas e possibilidades. Fortaleza: Sociedade Brasileira de Enfermeiros Escritores; 2005. p.57-71.

14 Barbosa LC, Martins MC, Silva VAG, Carvalho QCM. Dor na criança desnutrida: percepção da mãe. Rev Latino-am Enferm. 2005;1(4):596-8.

15 Gaiva MAM. O cuidar em unidades de cuidados intensivos neonatais: em busca de um cuidado ético e humanizado. Cogitare Enferm. 2006;11(1):61-6. 